\title{
Decálogo para la sostenibilidad de una organización apostólica
}

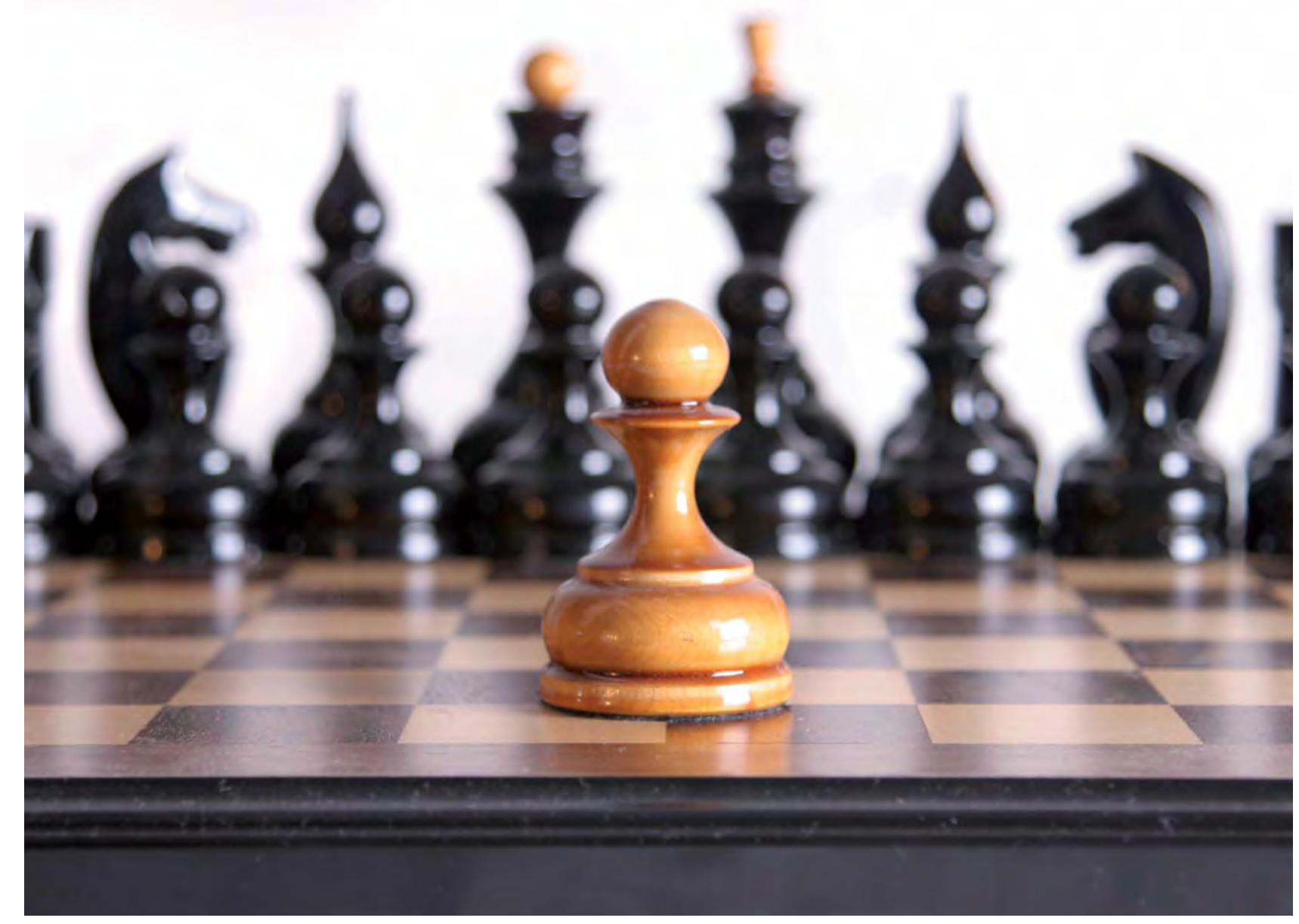

En este artículo se analizan los criterios que San Ignacio de Loyola estableció para que la organización que él fundó en 1540, la Compañía de Jesús, fuera sostenible en el tiempo. Como trabajo aplicado de liderazgo

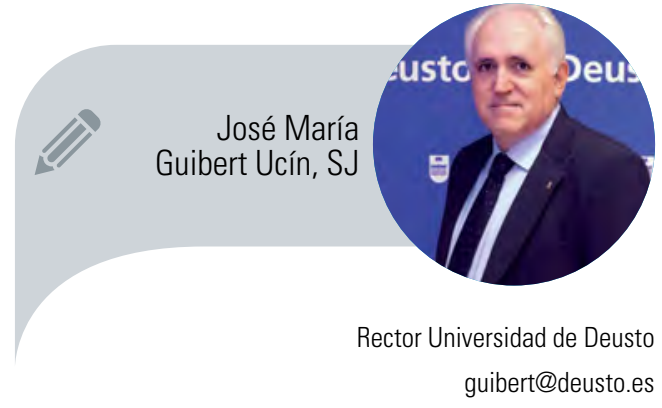
ignaciano actual, se busca una adaptación de dichos criterios a organizaciones de hoy en día, aunque vivamos en un contexto más laical y plural. 
¿Cómo hacer que una organización con un fin social (educativo, etc.) sea sostenible? ¿Aporta algo el que dicha organización tenga fines apostólicos? San Ignacio (Azpeitia 1491, Roma 1556) estableció un decálogo de criterios para que la organización que él creó en 1540, la Compañía de Jesús, fuera sostenible en el tiempo.

En este artículo se analizan esos criterios y se proponen para una organización actual. Se presenta esta temática como una reflexión necesaria hoy en día en las instituciones ignacianas y como clave en el concepto de liderazgo ignaciano.

El liderazgo ignaciano es un concepto que ha cuajado hace unos pocos años. $Y$ por ello hay publicaciones, cursos y distintas dinámicas de trabajo, hechos novedosos, que buscan profundizar y sacar provecho de esta idea. En el fondo, se trata de unir ambos conceptos creativamente: la tradición ignaciana (o jesuita) y el mundo del liderazgo.

De hecho, así se generan muchas veces las innovaciones en la vida social: poniendo un adjetivo al lado de un sustantivo con el que nunca antes estuvo ligado, o relacionando dos conceptos que previamente no se juntaban. Dos áreas de trabajo, conceptuales, de experiencias o de ideas distintas, que antes no dialogaban entre ellas, comienzan a verse de manera conjunta. La innovación muchas veces no consiste en hacer algo totalmente nuevo, que antes no existía, sino que se trata simplemente de poner en común, para que generen propuestas fecundas y ricas, dos áreas que antes iban cada una por su lado.

En nuestro caso se une el liderazgo (con lo que tiene de intuiciones empresariales o de gestión y de propuestas psicológicas o humanistas) y, por otro, la espiritualidad (en este caso, la ignaciana, recogiendo la experiencia de la vida y obra de san Ignacio de Loyola).

En el título de este artículo aparece un término ("sostenibilidad") que se utiliza también estos años con distintos fines. Añadir esta palabra en una reflexión sobre liderazgo ignaciano puede parecer que es rendirse a la moda, por querer uti-

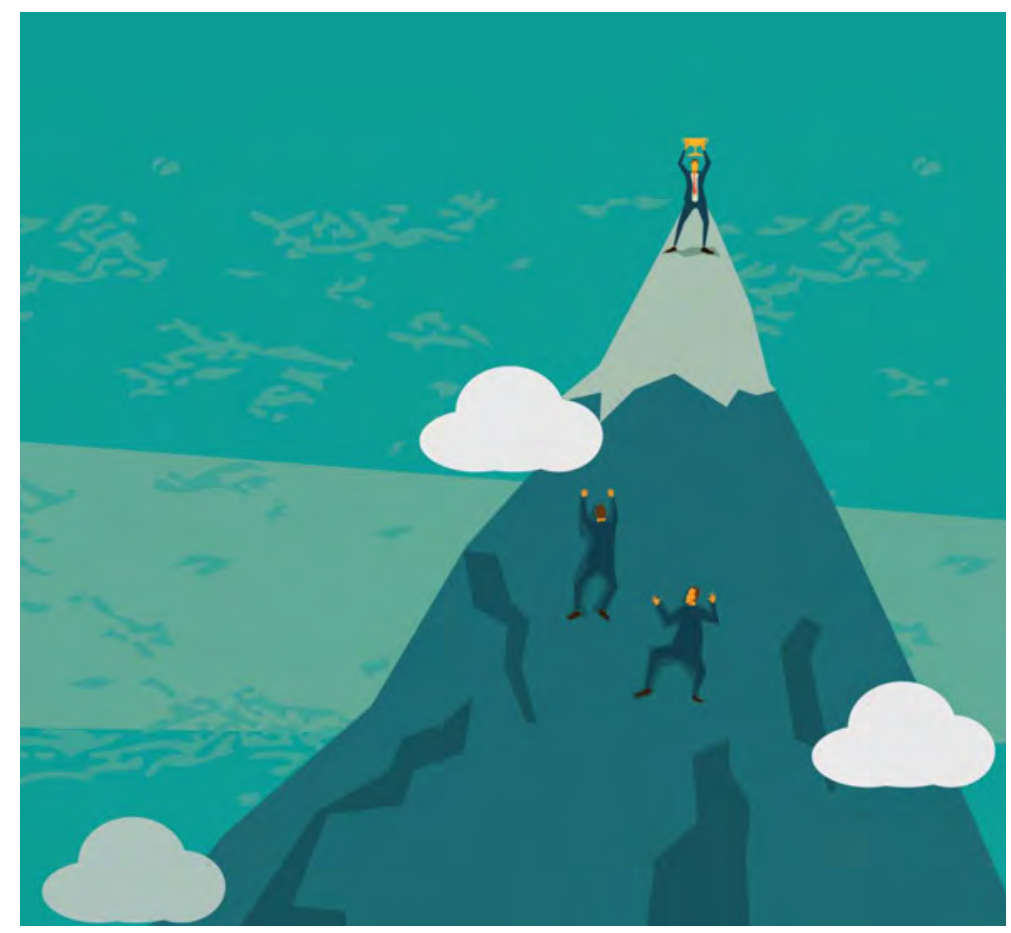

lizar para provecho propio uno de los conceptos que ahora se ven como relevantes y que aparecen por todas partes.

¿Utilizó san Ignacio (siglo XVI) el término "sostenibilidad" (de moda en el siglo XXI)? Podemos analizar qué se dice sobre sostenibilidad, o términos parecidos, en los estudios que se han hecho sobre san Ignacio, pues se han hecho bases de datos en las que se listan todas y cada de las palabras que empleó en sus escritos.

En las Ilamadas Concordancias de San Ignacio, una base de datos informática con quince textos de san Ignacio (todos los textos menos las cartas que escribió), están incluidos los términos "sostener", "sustentación", "sustentar", "sustento" o sustentatio. En total aparecen 17 veces. La mayoría de las veces el uso de estos términos tiene que ver con lo que hoy denominaríamos "sostenibilidad económica".

Sin embargo, hay otro término que va más allá de lo económico y material y hace referencia a la sostenibilidad una institución en su conjunto (en este caso, la Compañía de Jesús): su finalidad, su espíritu, su sentido, su estructura, etc. Se trata del vocablo "conservar" (y los relacionados: conservación o conservatio). Este conjunto de palabras aparece 45 veces y hacen referencia a contenidos de más riqueza que sólo el sustento material.

Este artículo se centra en una parte de las Constituciones de la Compañía de 


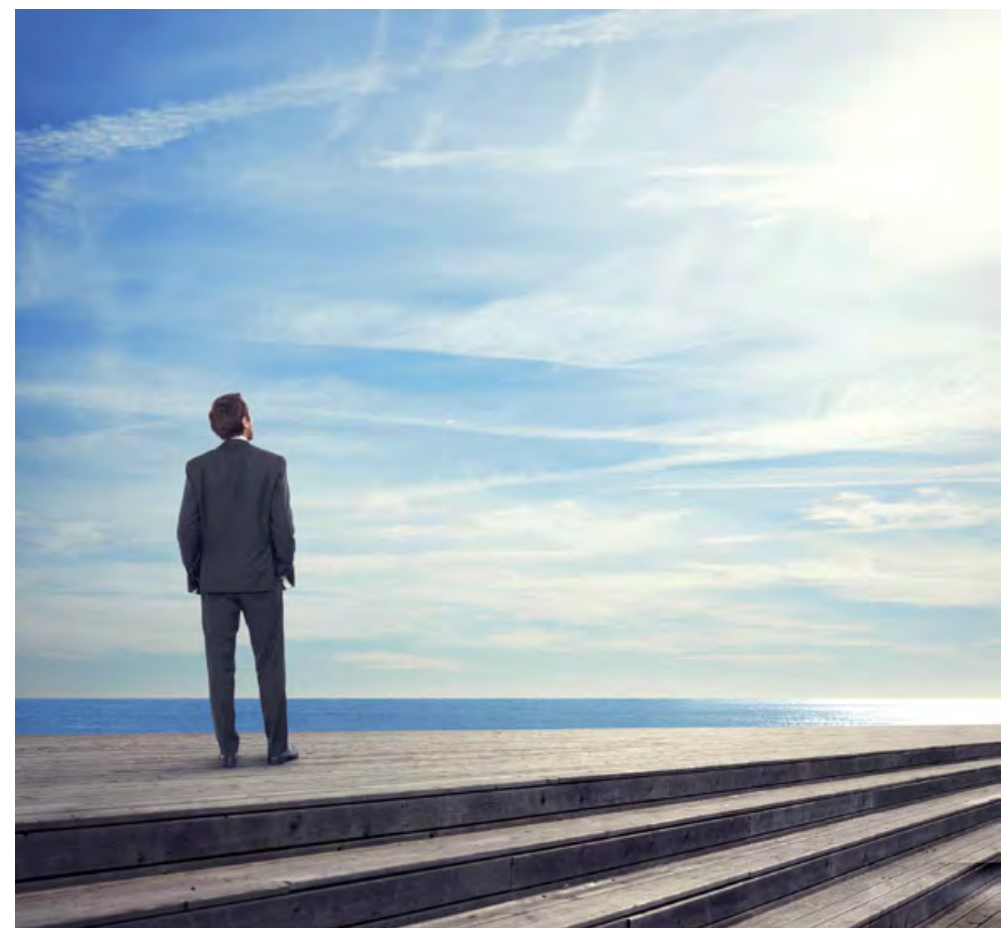

Jesús, que lleva como título "De cómo se conservará y aumentará todo este cuerpo en su buen ser". Se trata de la última parte, la décima. Después de describir todo el proceso de entrada de candidatos jesuitas a la Compañía, su formación, las áreas de misión, la estructura, los votos, el gobierno, etc., san Ignacio dedica la décima y última parte de las Constituciones a una visión de conjunto con una preocupación: todo lo que Dios ha hecho con nosotros, ¿será sostenible en el futuro?, ¿cómo ayudar a que así sea? Utiliza el término "conservación", pero lo tomo aquí como el equivalente a lo que hoy más bien denominamos "sostenibilidad". Por ello, este artículo consistirá en un comentario a dicha parte décima de las Constituciones.

Con un doble fin. Por un lado, presentarlo, es decir, hacer accesible algo que no es muy conocido. Por otro, interpretarlo o aplicarlo a nuestro contexto. Esto es más complicado, pues implícitamente quiere plantearse y responder a la pregunta de si lo dicho entonces sigue siendo sugerente o inspirador hoy en día, casi cinco siglos más tarde, en un contexto más plural y menos religioso que el de aquella época. ¿Lo que se decía para el conjunto de la Compañía de Jesús hace casi medio milenio tiene algo que ver con, por ejemplo, un colegio jesuita de hoy o con otra institución u organización actuales? Ésta es la pregunta que está detrás de este artículo. ¿Ayudan esos párrafos de las Constituciones al liderazgo ignaciano de organizaciones de hoy en día?

En los párrafos que siguen presento un listado de conceptos que aparecen en dicha "décima parte principal" de las Constituciones [números 812-827]. En lo que sigue, pongo entre comillas lo que es cita literal de ese texto, así podemos disfrutar de lo que se dice ahí. Al ser un texto muy antiguo, mi esfuerzo será el de explicarlo y actualizarlo. Con una observación: las instituciones de hoy en día (educativas, etc.) viven en un contexto menos religioso que el de hace medio milenio. Nuestros centros hoy son inspirados por lo religioso, no son religiosos en todo. Conviven con mentalidades más o menos laicas y no creyentes. Por ello, en algunos casos, buscaré cómo traducir lo que es claramente religioso a un lenguaje más laical o humanista genérico.

El decálogo que resulta de actualizar esta parte de las Constituciones tiene una jerarquía. Por un lado, están los tres primeros conceptos. Y dentro de ellos, el orden de importancia es secuencial. Después aparecen siete "ayudas" más que san Ignacio presenta para sostener "en su buen ser" la institución. Será entonces tarea del líder ignaciano aplicar esos conceptos a su institución para lograr "conservarla y aumentarla", es decir, hacerla sostenible.

\section{Esperanza}

El primer consejo que da san Ignacio, pensando en el futuro de la Compañía, es llamativo: "es menester en él [Dios] solo poner la esperanza de que él haya de conservar y llevar adelante lo que se dignó comenzar". El punto de partida de su modo de pensar es que "la mano" de Dios ha creado la Compañía. A través de todos los trabajos e ideas felices de san Ignacio y sus primeros compañeros, era Dios el que operaba por medio de ellos. Luego, ¿de quién depende la sostenibilidad de la Compañía? De Dios mismo. Dios dirá. Si Dios ha movido a una serie de personas, él tiene que seguir moviéndonos. Por eso, 
no hay que olvidar que detrás de todos nuestros esfuerzos por mejorar y ser sostenibles, hemos de ver la mano de Dios. O dicho de otra manera, hemos de dejar que sea esa luz divina la que nos haga trabajar, aunque sea en lo más material, por nuestra institución.

¿Cómo se puede poner esto en un mensaje más laical? Simplemente, invitando a la gente a confiar en la vida, en lo positivo de las personas. Los creyentes decimos que Dios está ahí siempre, que nos atiende siempre, que nos mueve hacia el bien siempre, que con lo que hagamos intentemos seguir su espíritu, que tengamos siempre esperanza en él. En lenguaje laical se puede decir que siempre hay que estar abiertos a la mejora, que nunca hay que absolutizar medidas concretas o que siempre hay que buscar propuestas holísticas y cuidar una libertad interior ante lo que se presente. Eso quiere decir tener esperanza en que con el bien obrar las cosas saldrán como el destino disponga. Siempre, porque sí, con actitud positiva y esperanzada, sean cuales sean los problemas. Los creyentes ponemos la esperanza en Dios, los que tienen otras creencias en la vida o la historia o la evolución, etcétera.

\section{Interioridad}

El segundo bloque de recomendaciones que hace san Ignacio para la Compañía tiene que ver con la vida interior: "Y conforme a esta esperanza el primer medio y más proporcionado será el de las oraciones". Y continúa: "Ios medios naturales que disponen el instrumento de Dios Nuestro Señor para con los próximos, ayudarán universalmente para la conservación y aumento de todo este cuerpo".

Siempre decimos que las personas son lo más importante de las organizaciones. Cuando decimos esto, estamos pensando implícitamente en la persona en toda su complejidad y riqueza. Si las personas no están centradas y motivadas en lo que la institución pretende, difícil que ésta salga adelante. La persona colabora en la institución con todo su ser: no somos robotitos que dedicamos al trabajo

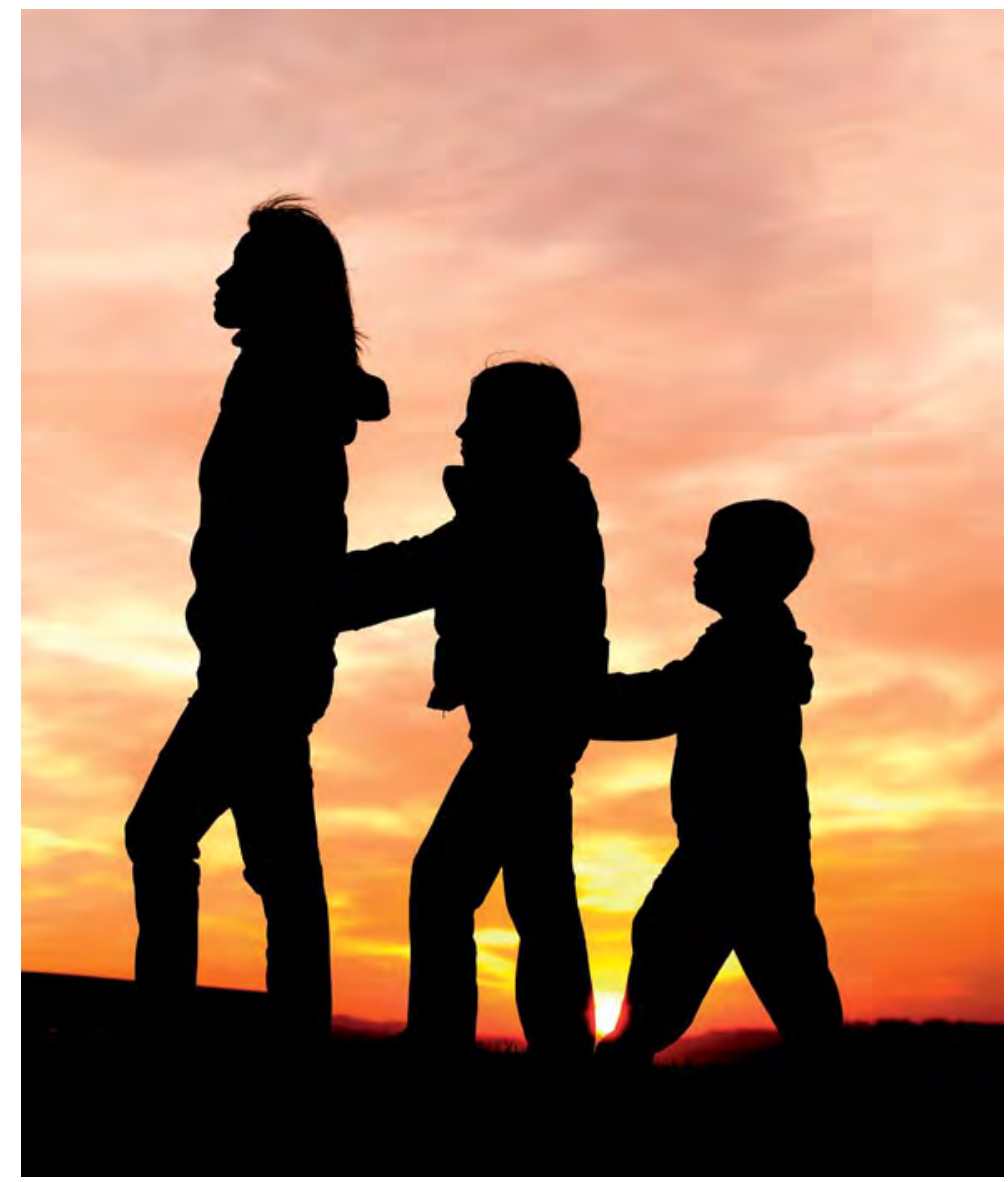

\section{Aprender a leer. A solas primero y, quizá, en \\ grupo después, aprender a asimilar de alguna \\ manera dentro de la propia vida}

las aportaciones de otras vidas

sólo una pequeña parte de lo que somos. Nuestra creatividad, motivación, imaginación, ideas, además del trabajo mismo, son necesarias para la sostenibilidad de nuestra organización.

Cuando san Ignacio habla de "oración" se refiere a lo interior de la persona. Si uno reza por algo, ese algo es parte de la vida de uno. Si uno reza por su organización y personas, esa organización y personas son parte de uno. No se puede rezar por algo sin implicarse personalmente.

Unido a la oración, san Ignacio hace referencia a: "bondad, virtud, caridad, pura intención, celo sincero". Estos son los "medios naturales" que nos "disponen" como instru- 


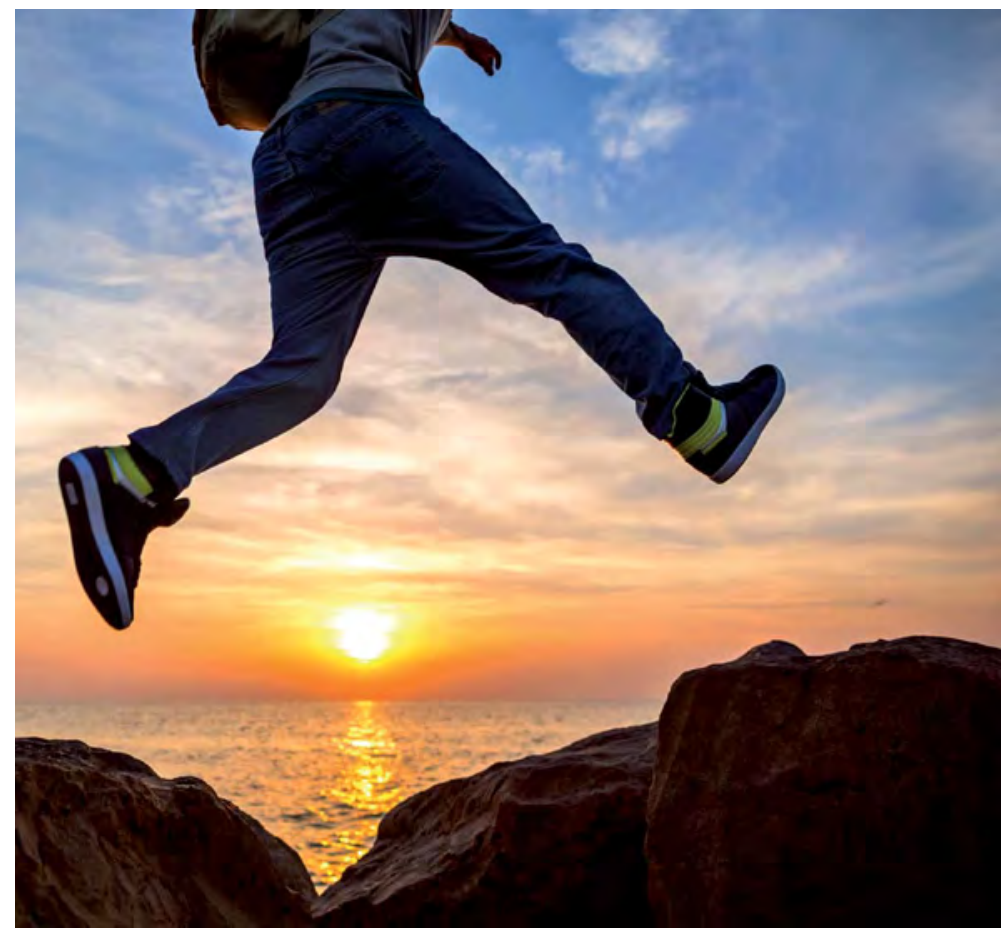

mentos de Dios para ayudar a los prójimos. La acción de Dios se da a través de lo bueno del ser humano. No hay milagros artificiosos que nos resuelven las cosas como por arte de magia. Más bien el milagro es tener esas actitudes de fondo.

Es decir, la clave para que la institución sea sostenible es la calidad humana de las personas que la componen. Esa calidad humana está llamada a estar formada de valores éticos, que san Ignacio denomina "las virtudes sólidas y perfectas". Estas virtudes "juntan el instrumento con Dios y le disponen para que se rija bien de su divina mano", muestran nuestra "familiaridad con Dios" y son la base de "las cosas espirituales". La vida espiritual nos ayuda a cuidar estas virtudes y, por medio de ellas nos acercamos a Dios y permitimos que actúe en nosotros y en la organización. La organización que quiere ser apostólica no sobrevivirá sin estas virtudes en las personas.

\section{Competencias}

San Ignacio siempre distingue entre lo interior y lo exterior: "aquellos [medios] interiores son los que han de dar eficacia a estos exteriores para el fin que se pretende". Los medios interiores ya los hemos revisado en el apartado anterior. Los medios exteriores son las "letras", la "doctrina fundada y sólida", el "modo de proponerla al pueblo en sermones y lec- ciones" y la "forma de tratar y conversar con las gentes".

Estas distintas competencias también tienen su relevancia, pero, como señalo, desde una jerarquía: lo interior mueve a lo exterior; si lo interior falla, lo exterior se utilizará probablemente mal. San Ignacio, como sabemos, era un experto en trabajar "lo interior". Él lo descubrió en sí mismo y es su principal aporte a la Iglesia y a la historia. Pero no descuida lo exterior.

Vemos que también valora las "letras" y la "doctrina". El vio pronto que sin formación académica se pueden lograr menos frutos. Además, como vivió en un momento turbulento, buscó basarse siempre en doctrina segura ("fundada y sólida"). Si la base es sólida, luego pueden hacerse múltiples aplicaciones y adaptaciones, pero distinguiendo qué es una adaptación y qué es la base. Por último, es de destacar que busca la adaptación y uso de las letras para "el pueblo" y "las gentes". No se queda en la pura especulación o en el saber por el saber o en la propia realización personal narcisista. Le preocupa más el bien de la gente que la posible erudición exquisita sin más de los apóstoles.

\section{Estructuras}

Además de los tres principales e insustituibles criterios ya presentados, san Ignacio presenta otras siete "ayudas". La primera de éstas hace referencia a las estructuras: "Asimismo, mucho ayudará mantener en su buen ser y disciplina los colegios". La Compañía pronto se implicó en crear instituciones, y éstas son estructuras que necesitan ser atendidas en cuanto tales. Son una complicación y una carga, pero posibilitan un servicio mayor y más estable. Otras órdenes religiosas se han implicado menos en estructuras apostólicas complejas. Los "colegios" de entonces son símbolo de estructuras apostólicas actuales (educativas, pastorales, sociales, culturales, etcétera). La atención a la burocracia, la gestión y la estructura misma de una institución hace posible la perdurabilidad del apostolado. Alguien tiene que atender esto. 


\section{Austeridad}

"Importará para la conservación y aumento de todo este cuerpo, que se destierre muy lejos toda especie de avaricia". El deseo de más dinero por parte de las personas o por parte de la institución misma es siempre un problema. También está el riesgo de corrupción, es decir de hacer que los recursos, rentas y fondos de un centro no se usen para lo que está establecido ("convertir en su utilidad la renta de los colegios").

San Ignacio lo tiene claro. Pensando en las órdenes religiosas, la pobreza "las conserva en su ser y disciplina y las defiende de muchos enemigos, y así el demonio procura deshacerle por unas o por otras vías". Por eso, en las instituciones se ha de invitar siempre a trabajar la austeridad al pensar en sus recursos. Y el control del uso de los mismos.

\section{Humildad}

Por experiencia propia, san Ignacio tenía especial sensibilidad hacia las situaciones en las que alguien quiere trepar o ambiciona puestos de manera desordenada: "Será también de suma importancia para perpetuar el bien ser de la Compañía, excluir de ella con grande diligencia la ambición, madre de todos males en cualquiera comunidad o congregación". En todos sus escritos fomenta la humildad y el servicio.

\section{Selección}

"Para que se perpetúe el bien ser de todo este cuerpo, hace mucho lo dicho [en otras partes de las Constituciones] del no admitir turba ni personas que no sean aptas para nuestro instituto, aun a probación; y cuando algunas se hallasen, durante el tiempo de la dicha probación despedirlas. Y mucho menos deben retenerse personas viciosas o incorregibles". Como es de esperar, seleccionar bien a las personas es muy importante para la misión.

Lo que san Ignacio quiere, y todos queremos siempre es: "personas escogidas en espíritu y doctrina, y muy a la larga ejercitadas y conocidas en varias pruebas

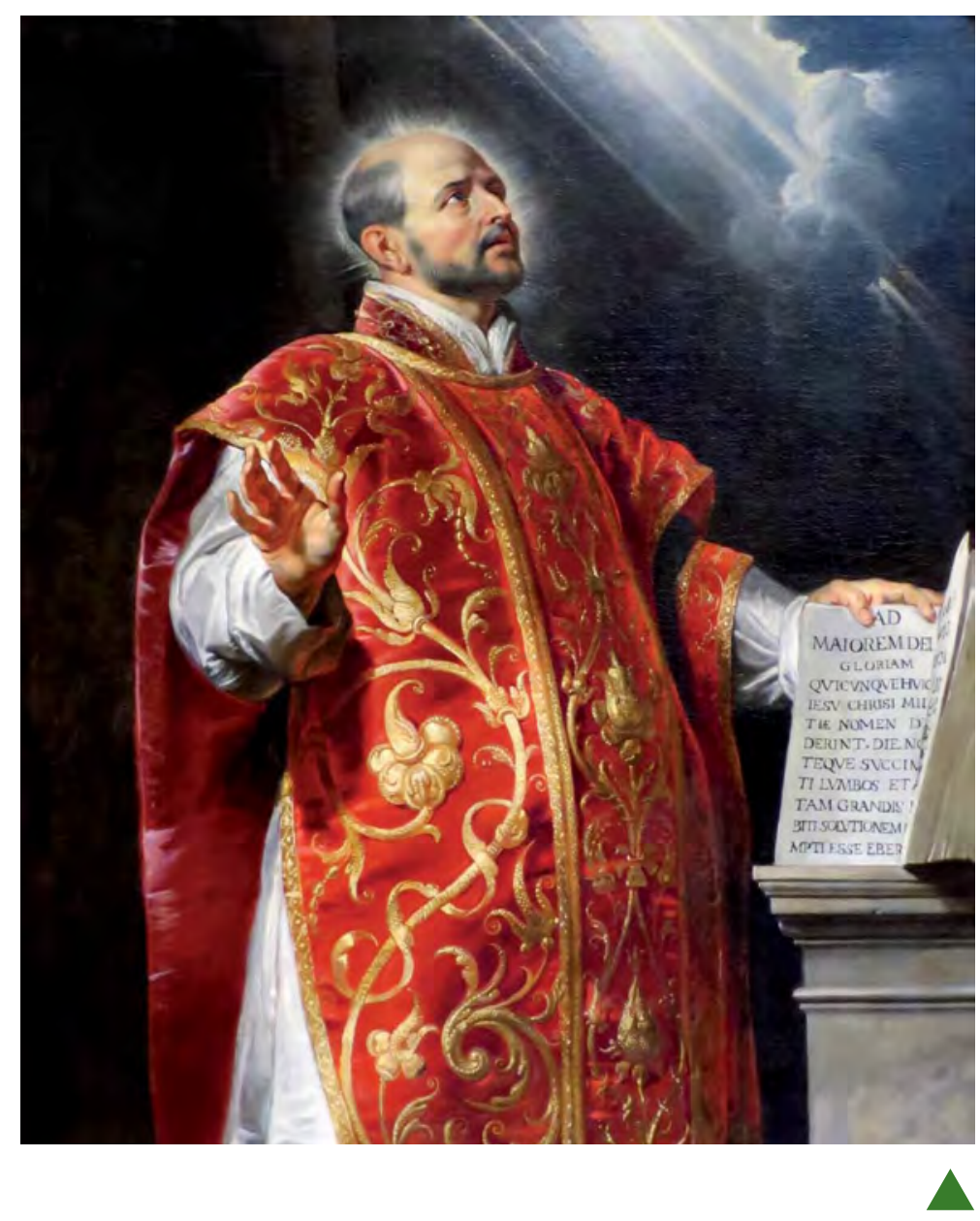

de virtud y abnegación de sí mismos con edificación y satisfacción de todos". La causa está clara: "porque de esta manera, aunque se multiplique la gente, no se disminuya ni debilite el espíritu".

En el apartado de seleccionar personas, destaca por su relevancia ("sumamente importa") la elección de cargos y responsables, ya que "el bien o mal ser de la cabeza redunda a todo el cuerpo". Por ello, los procesos de selección de las personas con responsabilidad y las competencias que tienen como autoridad son temas a establecer con delicadeza.

\section{Unión}

"Mucho también ayudará para conservar el buen ser de ella [la Compañía], (...) el vínculo de las voluntades, que es la caridad y amor de unos con otros". La unión entre las personas dentro de la casa es algo a cuidar y no hay que darlo por supuesto. $Y$ ya en aquellos tiempos se preocupó de algo sobre lo que hoy en día también se escuchan quejas: la comunicación interna ("sirve el tener noticia y nuevas unos de otros y mucha comunicación").
Peter Paul Rubens [Public domain], via Wikimedia Commons 


\section{Flexibilidad}

San Ignacio puede parecer a veces muy exigente, pero luego pide moderación en el trabajo: "La moderación de los trabajos espirituales y corporales, y mediocridad en las Constituciones, que no declinen a extremo de rigor o soltura demasiada (y así se pueden mejor guardar), ayudará para el durar y mantenerse en su ser todo este cuerpo". Y curiosamente dice que no seamos demasiado fundamentalistas al aplicar las mismísimas Constituciones. No todo se logra a base de tener buenos reglamentos de organización interna. Hay que tenerlos, sí, pero hay que saber aplicarlos con flexibilidad y prudencia.

\section{Relaciones exteriores}

El último punto a destacar es la indicación de que no busquemos ser generosos con los de dentro de nuestra institución y a la vez egoístas con los de fuera: "A lo mismo en general sirve procurar de mantenerse siempre en el amor y caridad de todos, aun fuera de la Compañía".

Y tratemos a todos por igual, sin diferencias: "no haya ni se sienta en la Compañía parcialidad a una parte ni a otra entre los príncipes o señores cristianos, antes un amor universal que abrace a todas partes (aunque entre sí contrarias) en el Señor Nuestro". Los grandes valores humanos hay aplicarlos con los amigos, con los compañeros de trabajo y con las personas de fuera de nuestra organización. El egoísmo no ayuda a la sostenibilidad.

En conclusión, podemos señalar que la sostenibilidad de las organizaciones es

\section{(D) DARA SABER MÂS}

Arzubialde, S., Corella, J. y García Lomas, J.M. (eds.) (1993). Constituciones de la Compañía de Jesús. Introducción y notas para su estudio. Bilbao-Santander: Mensajero-Sal Terrae.

GuiBERT, J.M. (2014). Diccionario de liderazgo ignaciano. Bilbao: Ediciones Mensajero.

LoWnEY, C. (2014). El liderazgo de los jesuitas: autoconciencia, ingenio, amor, heroísmo. Santander: Sal Terrae. algo que debe preocupar a sus líderes, que siempre han de ir más allá del día a día o visión cortoplacista y hacerse las preguntas de fondo que sean pertinentes. Al inspirarnos en un líder como san Ignacio observamos que se planteó seriamente el futuro de la principal organización que creó en su vida. Dejó escrito que esa sostenibilidad o conservación pasa en primer lugar por actitudes humanas y espirituales de fondo que él a veces denomina medios interiores (la actitud de esperanza profunda en lo que se hace, el cuidado de la interioridad y la calidad humana y ética de las personas) y por medios exteriores (conocimientos serios y modo de aplicarlos). Por otro lado, plantea siete ayudas a la organización que también componen un marco para pensar en el talante propio de una institución. Esto lo planteó evidentemente desde una visión cristiana confesional, pero tiene una fácil traducción a planteamientos humanistas más generales. Todo esto ha servido y sirve para que la Compañía de Jesús siga en pie casi medio milenio después (en 2015 ha celebrado su 475 cumpleaños). El secreto de esta sostenibilidad está en la fidelidad a la identidad y misión propias. Esto no es algo íntimo, subjetivo, secreto y muy personal o intransferible de las personas de la organización, sino que ha de saber traducirse, como hemos visto en los párrafos anteriores, en valores y principios que inspiren a una organización y a sus estructuras •

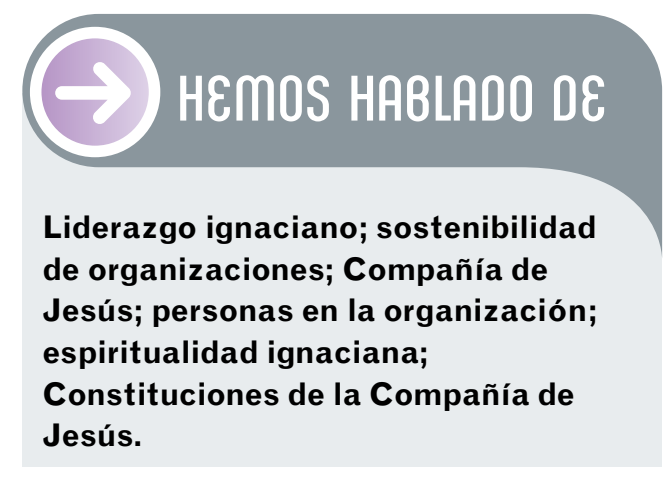

Este artículo fue solicitado por PADRES y MAESTROS en junio de 2015, revisado y aceptado en septiembre de 2015. 


\section{¿Cómo orientar profesionalmente a tu hijo? \\ Manual práctico para padres}

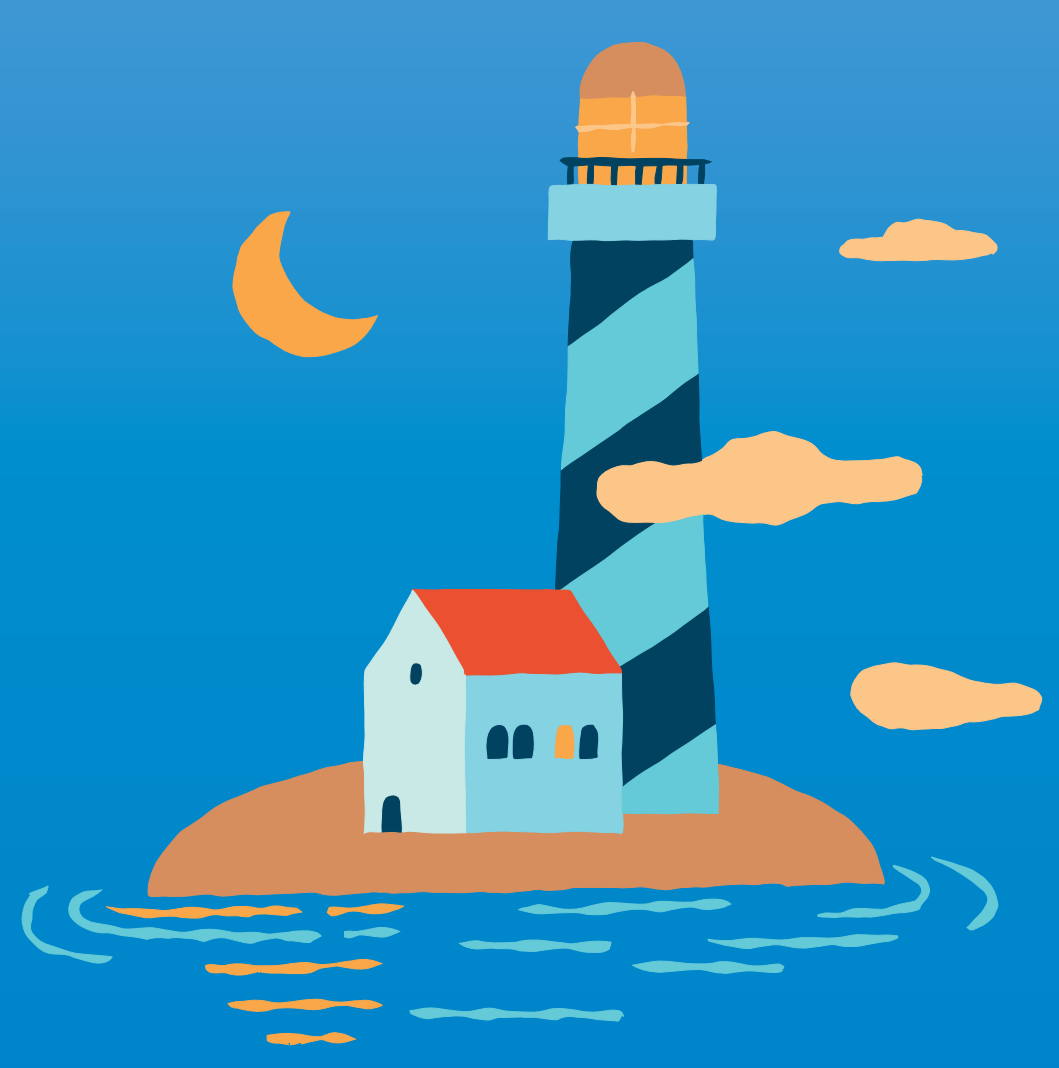

Vicente Hernández Franco (Coord.)

Fundación Bertelsmann

El objetivo principal que tiene esta guía práctica de Orientación Profesional para padres es ofrecer a las familias la información relevante para que puedan formarse su propio criterio a la hora de entender, enfocar y asesorar, desde la responsabilidad parental, todo el proceso de

Orientación Profesional de sus hijos.

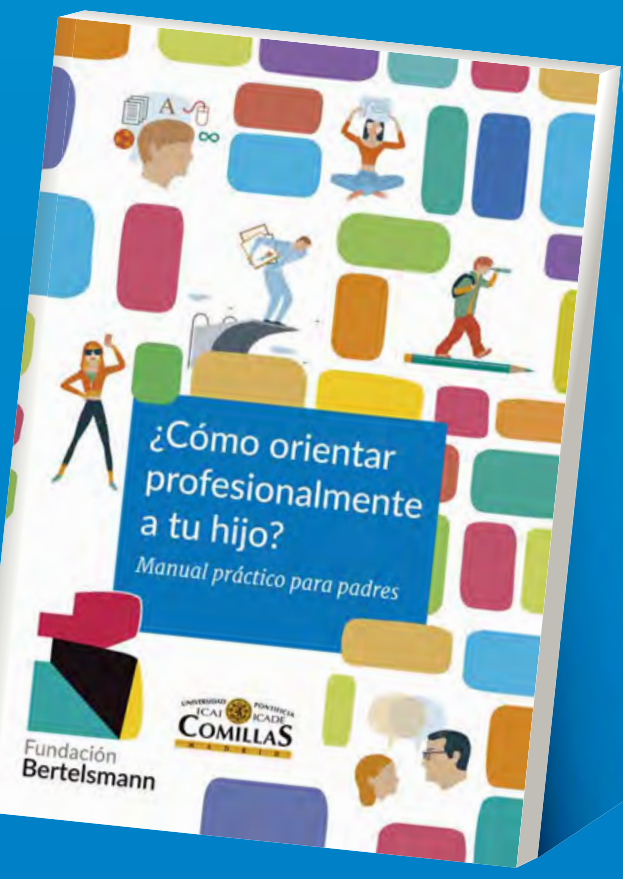

Por el empleo juvenil

Puedes descargar gratuitamente el libro

Tel.: +34932687373 en versión pdf: https://goo.gl/RMcZIR

info@fundacionbertelsmann.org

Cómo seguirnos

www.fundacionbertelsmann.org

@FBertelsmann

www.facebook.com/FundacionBertelsmann

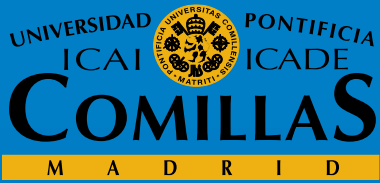

